\title{
Implementasi WebGIS untuk Pemetaan Objek Wisata Kota Jakarta Barat dengan Metode Location Based Service menggunakan Google Maps API
}

\author{
I Made Prasatya Mertha ${ }^{1}$, Vincent Simadiputra ${ }^{1}$, Eko Setyawan $^{1}$, Suharjito $^{2}$ \\ ${ }^{I}$ Mahasiswa Computer Science Department, BINUS Graduate Program - Master of Computer Science, Bina Nusantara University, Jakarta, Indonesia \\ 11480
}

${ }^{2}$ Dosen Computer Science Department, BINUS Graduate Program-Master of Computer Science, Bina Nusantara University, Jakarta, Indonesia 11480

\section{KEYWORDS}

Framework CodeIgniter, Google Maps API,
Location Based Service, WebGIS

Location Based Service, WebGIS

\section{CORRESPONDENCE}

E-mail: i.mertha@binus.ac.id

\section{PENDAHULUAN}

Indonesia adalah negara kepulauan yang dikenal memiliki potensi wisata yang sangat besar. Wisata budaya dan sejarah adalah salah satu dari jenis-jenis wisata yang sangat populer di Indonesia. Banyak sekali wisatawan asing yang berkunjung ke Indonesia untuk mengetahui wisata budaya dan sejarah serta adat istiadat daerah di Indonesia. Hal tersebut terbukti dengan besarnya pendapatan Negara pada sektor pariwisata tiap tahunnya. Bahkan sektor pariwisata ini mampu menjadi salah satu yang pantas diunggulkan di Indonesia dalam rangka menyongsong Masyarakat Ekonomi ASEAN (MEA). Namun, di sisi lain upaya dalam melakukan promosi wisata dirasa masih kurang. Terutama bagi wisatawan mancanegara maka yang paling dikenal dari Indonesia adalah Bali, padahal masih banyak tempat wisata lain yang bisa bersaing tetapi kurang adanya informasi terkait wisata tersebut.
Salah satu daerah yang mempunyai potensi wisata adalah kota Jakarta Barat. Jakarta Barat merupakan salah satu dari 5 kota administrasi yang berada di wilayah Provinsi DKI Jakarta bersama Jakarta Timur, Jakarta Utara, Jakarta Selatan dan Jakarta Pusat. Kota administrasi Jakarta Barat dipimpin oleh seorang walikota didampingi oleh wakil walikota yang pengangkatannya dilakukan oleh gubernur dan diambilkan dari kalangan Pegawai Negeri Sipil (PNS) [1]. Jakarta Barat dikenal sebagai kota yang mempunyai bangunan-bangunan bersejarah peninggalan masa kolonial Belanda, seperti gedung balai kota, kawasan pecinan dan sejumlah masjid tua serta benteng-benteng pertahanan pada masa pendudukan Belanda di Batavia. Untuk melestarikan bangunan warisan sejarah tersebut, pemerintah kota Jakarta Barat telah mencanangkan salah satu misinya yaitu untuk membangun tata pemerintahan yang baik guna terwujudnya kota jasa dan wisata budaya dan sejarah [1]. Tentunya hal ini tidak bisa serta merta diwujudkan oleh pemerintah kota itu sendiri, dibutuhkan peran serta masyarakat terutama warga yang berdomisili di Jakarta Barat untuk ikut mempromosikan wisata yang ada di kota Jakarta 
Barat terutama wisata budaya dan sejarah. Tetapi, pada kenyataannya masih sedikit warga kota Jakarta Barat khususnya yang peduli terhadap hal tersebut. Meskipun di internet banyak ditemukan website atau blog yang mengulas informasi mengenai wisata di Jakarta Barat, tetapi penyajiannya masih kurang lengkap dan tidak disertakan rute perjalannya. Masih banyak juga lokasi wisata di Jakarta Barat yang belum banyak masyarakat yang mengetahuinya karena minimnya publikasi. Hal ini sungguh merupakan sebuah ironi mengingat kota Jakarta Barat juga dikenal sebagai kota wisata sejarah dan budaya.

Oleh karena itu diperlukan sebuah langkah kongkrit untuk ikut melakukan promosi wisata kota Jakarta Barat, salah satunya memanfaatkan teknologi internet. Dewasa ini internet sudah menjadi sebuah kebutuhan dan biaya penggunaannya semakin lama semakin terjangkau. Hal ini akan sangat mendukung upaya promosi wisata dengan cara memanfaatkan teknologi website berbasis Sistem Informasi Geografis atau yang lebih dikenal dengan istilah webGIS. Langkah ini juga diambil oleh Hasan [2] yang melihat potensi wisata di kabupaten Lombok Timur yang merupakan kota wisata yang sudah terkenal di mancanegara tetapi belum mempunyai sistem yang mengaturnya. Sehingga dia membuat penelitian yang menghasilkan sebuah webGIS wisata menggunakan Google Maps API

WebGIS adalah sebuah aplikasi yang merupakan gabungan antara web design dan web pemetaan [3]. Dengan menggunakan teknologi WebGIS dapat dengan mudah ditampilkan peta wisata di wilayah tertentu yang dilengkapi dengan ulasan terhadap objek wisata tersebut dan disajikan dalam sebuah website. Keunggulan dari webGIS yang lain adalah lebih mudah dalam menyajikan data spasial yang bisa diakses secara online tanpa menggunakan bantuan software GIS [4]. Dengan demikian webGIS adalah pilihan yang tepat dalam mengaplikasikan ide dari penelitian ini. Berdasarkan permasalahan tersebut, perlu dilakukan penelitian dengan memetakan objek wisata kota Jakarta Barat menggunakan metode Location Based Service yang memanfaatkan Google Maps API dan menampilkannya dalam bentuk webGIS yang bisa diakses masyarakat melalui browser internet. Penggunaan metode tersebut dapat memudahkan dalam menentukan titik-titik lokasi wisata dengan menginput koordinat lattitude dan longitude yang didapatkan dari aplikasi Google Maps.

Penelitian ini bertujuan untuk menghasilkan sebuah webGIS yang berisi peta wisata di kota Jakarta Barat yang bisa diakses secara online melalu browser internet. Objek wisata yang akan ditampilkan tidak hanya wisata budaya dan sejarah tetapi dilengkapi juga dengan wisata kuliner, wisata belanja, wisata keluarga dan wisata religi. Dengan adanya webGIS ini diharapkan bisa memberikan informasi peta wisata kepada masyarakat atau calon wisatawan yang akan berkunjung ke kota Jakarta Barat, sekaligus bisa menjadi media promosi wisata yang ada di wilayah kota Jakarta Barat.

\section{Penelitian yang Terkait}

Dalam beberapa tahun terakhir, banyak metode webGIS yang dikembangkan pada sektor pariwisata sehingga banyak penelitian yang bisa dijadikan acuan dalam penelitian ini. Dafid [5] mengolah potensi aplikasi teknologi geospasial yang dijadikan sumber informasi berbasis webGIS dengan mengeksplorasi informasi wisata secara rinci di kota Malang. Penelitian ini menghasilkan sebuah portal webGIS yang dinamis yang bisa diperbarui sesuai situasi yang ada dan digunakan untuk membantu wisatawan agar mudah mengetahui lokasi wisata di kota Malang. Berbeda dengan penelitian yang dilakukan Sholeh [6], yaitu dengan memanfaatkan sistem informasi geografis untuk membuat web boarding yang bertujuan untuk memudahkan calon wisatawan dalam mengunjungi goa yang ada di wilayah Daerah Istimewa Yogyakarta. Pada penelitian ini menggunakan Google Maps API sebagai teknologi utama sehingga informasi mengenai goa dapat diakses melalui internet.

Penelitian sejenis juga dilakukan oleh Galih [7], yang membahas sistem informasi geografis dengan menyajikan data-data berisi fasilitas kesehatan di kecamatan Dayeuhkolot Bandung berbasis web. Dalam penelitian tersebut juga memanfaatkan Google Maps API dalam menampilkan petanya tetapi tidak disertakan detail pembahasan tentang struktur webGISnya. Dengan mengacu pada penelitian sebelumnya tersebut, maka penelitian ini dibuat menggunakan metode Location Based Service dengan memanfaatkan Google Maps API. Adapun pembahasannya ditambahkan detailnya terutama pada pembuatan webGIS. Sehingga diharapkan selain untuk menghasilkan webGIS wisata sesuai tujuan penelitian, juga bisa dijadikan rujukan bagi peneliti lain yang mengambil tema sejenis.

\section{METODE PENELITIAN}

\section{Tahapan Penelitian}

Penelitian ini terdiri dari 4 tahapan, yaitu persiapan, pengumpulan data, pengolahan data, hasil dan analisa. Secara lengkap tahapan penelitian ini dapat dilihat pada gambar 1. Pada tahap persiapan, dilakukan identifikasi dan perumusan masalah kemudian melakukan studi literatur. Dalam tahap ini dilakukan pencarian sumber data berupa artikel, buku dan jurnal terkait yang sesuai dengan topik penelitian ini sebagai pembanding dan materi tambahan pada penelitian ini.

Tahap kedua yakni pengumpulan data, data yang digunakan adalah data spasial berupa peta wilayah kota Jakarta Barat dan titik koordinat lokasi wisatanya. Titik koordinat dilakukan pencariannya melalui aplikasi Google Maps. Target penelitian ini adalah mendapatkan 50 titik lokasi wisata yang berada di wilayah lokasi penelitian. Kemudian data non spasial berupa data wisata yang meliputi wisata budaya dan sejarah, wisata kuliner, wisata belanja, wisata keluarga dan wisata religi yang didapatkan dari website pemerintah kota dan sumber lain di internet yang terpercaya.

Tahap ketiga yaitu pengolahan data, pada tahap ini data yang sudah terkumpul pada tahap sebelumnya dilakukan pengolahan data spasial dan pembuatan database. Sebelum membuat webGIS, terlebih dahulu dilakukan perancangan sistemnya yang berupa diagram use case untuk memudahkan pembuatan aplikasi webGIS. Kemudian langkah selanjutnya adalah pembuatan webGIS yang akan dijelaskan secara detail pada bahasan pengolahan data.

Tahapan keempat atau terakhir yaitu hasil dan analisa, dalam tahap ini dilakukan uji program dan uji usability atau kebergunaan aplikasi webGIS wisata ini. Pada uji program, 
dilakukan pengujian terhadap aplikasi webGIS dengan cara membuka aplikasi melalui browser internet menggunakan perangkat desktop maupun smartphone. Sedangkan pada tahap uji kebergunaan, digunakan kuisioner online dengan target 40 responden baik yang berdomisili di Jakarta Barat maupun di luar Jakarta Barat. Responden dipilih secara acak kepada pengguna internet melalui media sosial online. Hasil uji kebergunaan tersebut sangat menentukan apakah aplikasi webGIS ini sudah sesuai dengan tujuan pembuatan ataukah belum.

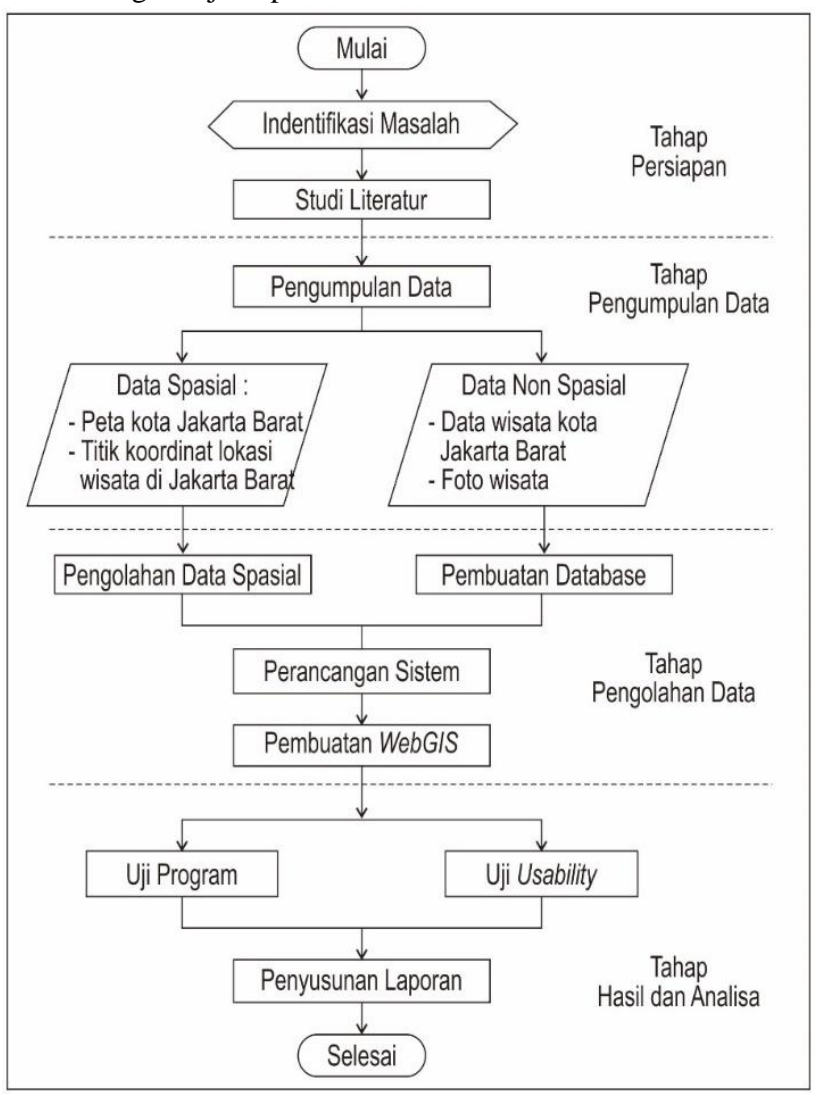

Gambar 1. Diagram Alur Tahapan Penelitian

\section{Data Penelitian}

Data pada penelitian ini terdiri dari data spasial dan nonspasial. Data spasial berupa peta lokasi wilayah penelitian dan titik koordinat lokasi wisata di kota Jakarta Barat yang diambil dari Google Maps. Pencarian data koordinat dilakukan dengan cara memasukkan kata kunci wisata tertentu ke dalam aplikasi Google Maps yang diakses secara online melalui laman http://map.google.com. Kemudian hasil pencarian tersebut ditemukan titik lokasi koordinat dan dicatatlah koodinat berupa lattitude dan longitudenya.

Sedangkan data nonspasial terdiri dari data primer dan data sekunder. Data primer berupa data wisata di kota Jakarta Barat yang didapatkan dari website pemerintah kota dan sumber lainnya di internet. Data yang diambil berupa foto tempat wisata dan profil singkat yang berisi sejarah berdirinya, alamat, nomor yang bisa dihubungi dan rute perjalanan ke lokasi wisata tersebut. Kemudian data sekunder diambil dengan cara mencari literatur seperti artikel, buku dan jurnal terkait dengan topik penelitian. Data sekunder ini digunakan untuk pembanding dan sebagai bahan pendukung dalam melakukan penelitian ini.

\section{Metode Location Based service}

Location Based Servis (LBS) adalah sebuah layanan berbasis lokasi yang bisa mengidentifikasi objek terentu dan menampilkan posisi lokasinya. LBS dapat diakses pada perangkat mobile dengan media internet [8]. Layanan LBS meninikberatkan posisi pengguna dengan cara memanfaatkan posisi sel jaringan atau dengan teknologi Global Positioning System (GPS). LBS menggunakan koordinat lattitude dan longitude dalam menentukan titik lokasi pengguna [9].

Metode dalam penelitian ini menggunakan LBS dengan Google Maps API. Google Maps adalah sebuah layanan yang diberikan secara gratis oleh Google. Layanan ini berisi peta dunia yang bisa kita manfaatkan untuk melihat atau menampilkan suatu daerah menggunakan suatu browser. Pengguna Google Maps bisa dengan mudah menampilkan peta di halaman web atau blog dengan menggunakan Google Maps API. Google Maps API sendiri merupakan suatu library yang berbentuk JavaScript [10]. Di dalam struktur codeIgniter Google Maps v3 library terdapat API key yang bisa didapatkan secara gratis melalui aplikasi Google Maps dengan mengunjungi laman https://code.google.com/apis/console. API key ini dibutuhkan untuk menampilkan peta Google Maps di dalam halaman web. Berikut kode API yang ada di struktur CodeIgniter Google Maps v3:



Struktur webGIS pada penelitian ini memanfaatkan kerangka atau Framework CodeIgniter (CI), dimana LBS dalam CI menggunakan Codeigniter Google Maps v3 API Library sebagai struktur kode untuk meninput lokasi wisata pada webGIS wisata Jakarta Barat.

\section{Pengolahan Data}

Tahap pengolahan data dimulai dengan membuat database dari data wisata yang sudah didapatkan pada tahap sebelumnya. Pembuatan database menggunakan phpMyAdmin dengan localhost XAMPP. Database ini kemudian dimasukkan dalam struktur kode pada framework codeIgniter dan dilakukan proses coding menggunakan notepad++. Apabila proses coding berhasil maka akan menghasilkan webGIS wisata Jakarta Barat yang bisa tampil melalui localhost. Langkah selanjutnya yaitu mendaftarkan domain dan hosting dan dilakukan proses upload data ke webhosting menggunakan bantuan FTP FileZilla. Setelah webGIS bisa tampil secara online melalui internet maka dilakukan uji sistem dan uji usabilitas atau uji kebergunaan. Hasil uji kebergunaan ini kemudian dilakukan analisa hasil sehingga didapatkan hasil akhir laporan tertulis tentang aplikasi webGIS wisata Jakarta Barat ini. Proses pengolahan data dapat dilihat pada diagram gambar 2 berikut : 




Gambar 2. Diagram Alur Pengolahan Data

\section{HASIL DAN PEMBAHASAN}

\section{Lokasi Penelitian}

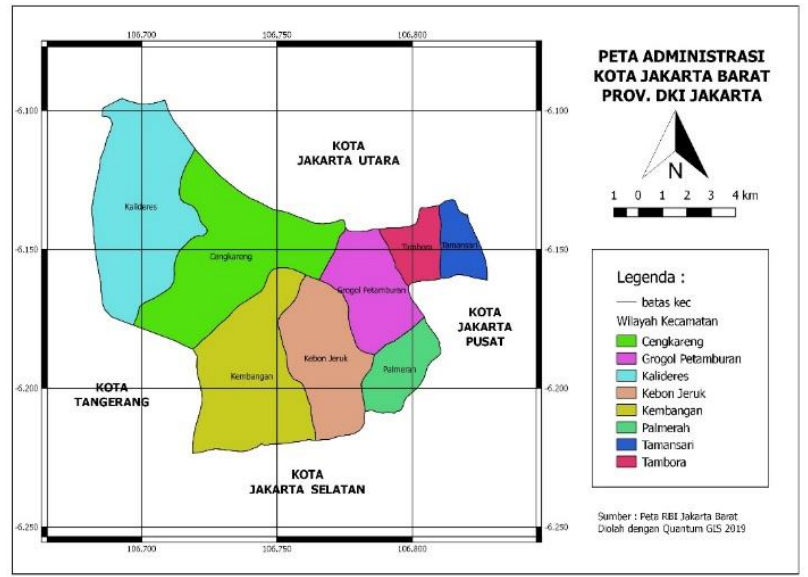

Gambar 3. Peta Administrasi Kota Jakarta Barat

Lokasi penelitian ini adalah di wilayah kota administrasi Jakarta Barat. Kota ini mempunyai luas wilayah : 12.615,14 Ha dan terletak antara 106 - 48 BT, 60 - 12 LU. Dilihat dari sisi geografis Jakarta Barat berbatasan dengan kabupaten/kodya Tangerang dan kota administrasi Jakarta Utara di sebelah utara dan berbatasan dengan kota administrasi Jakarta Selatan dan kabupaten/kodya Tangerang di sebelah selatan. Sedangkan di sebelah barat berbatasan dengan kabupaten/kodya Tangerang dan si sebelah timur berbatasan dengan kota administrasi Jakarta Utara dan Jakarta Pusat [1]. Secara administratif Jakarta Barat terdiri dari 8 Kecamatan, yaitu kecamatan Cengkareng, Grogol Petamburan, Taman Sari, Tambora, Kebon Jeruk, Kalideres, Palmerah dan kecamatan Kembangan. Dari 8 kecamatan tersebut terbagi menjadi 56 kelurahan [2]. Peta administrasi wilayah Jakarta Barat dapat dilihat pada gambar 3 .

\section{Perancangan Sistem}

Perancangan sistem sangat dibutuhkan dalam memulai pembuatan sistem atau aplikasi. Dalam hal ini dilakukan analisis kebutuhan fungsional pada sistem yang akan dibuat dengan cara menggunakan diagram use case. Diagram use case adalah sebuah kegiatan yang dilakukan oleh sistem yang dibuat karena adanya permintaan dari pengguna sistem. Use case biasanya terdiri dari stik figure atau aktor dan garis yang menghubungkan aktor dengan rincian fungsi sistemnya [11]. Salah satu fungsi dari usecase diagram adalah untuk merekam persyaratan fungsional suatu sistem [12].

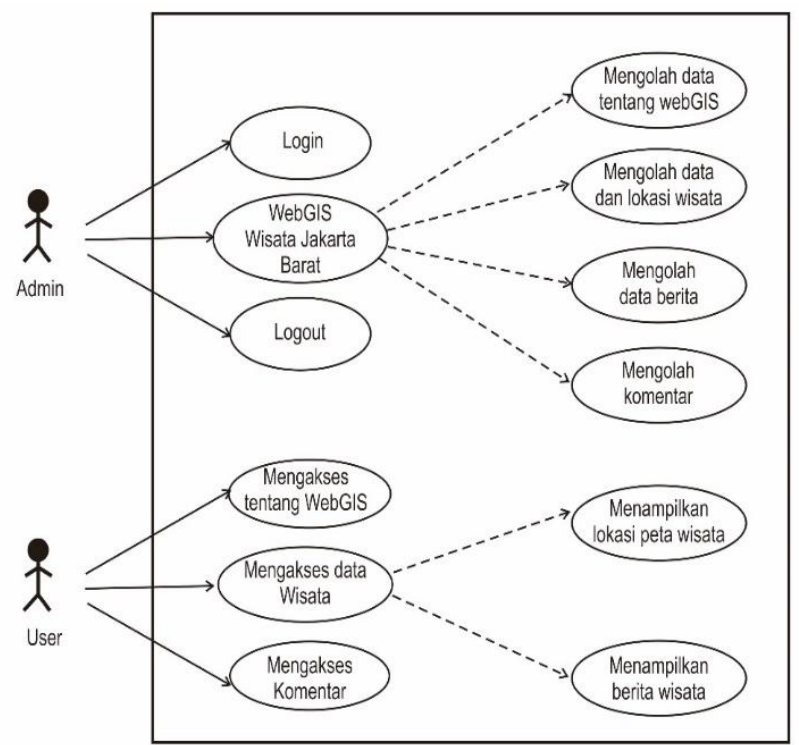

Gambar 4. Diagram Use Case

Pada gambar 4 dapat dijelaskan bahwa terdapat dua aktor utama yaitu admin dan user. Aktor admin mempunyai akses untuk melakukan login, mengolah data tentang webGIS, mengolah data dan lokasi wisata, mengolah berita dan mengolah komentar pada webGIS. Sedangkan pada aktor user bisa mengakses tentang webGIS, akses data wisata dan mengakses ataupun menuliskan komentar.

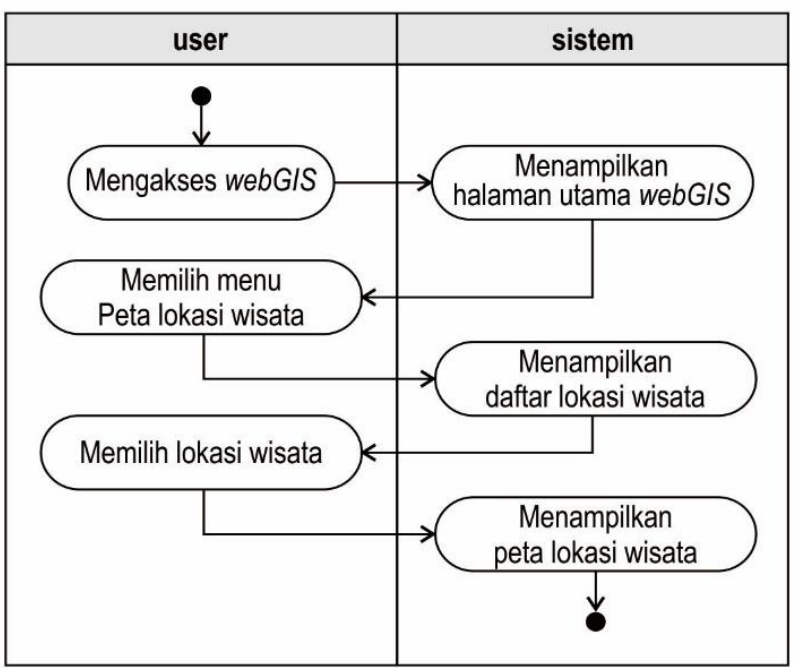

Gambar 5. Activity Diagram Melihat Lokasi Wisata 
Activity diagram menggambarkan proses yang bisa dilakukan baik oleh user maupun admin. Pada gambar 5 digambarkan activity diagram melihat lokasi wisata. Apabila user mengakses webGIS wisata Jakarta Barat maka sistem akan menampilkan halaman utama webGIS. User memilih menu peta lokasi wisata maka sistem akan menampilkan halaman daftar lokasi wisata. Kemudian user memilih lokasi wisata maka sistem akan menampilkan peta lokasi wisata yang dipilih. Adapun skema relasi yang menggambarkan hubungan antar tabel dapat dilihat pada ER Digram pada gambar 6 berikut.

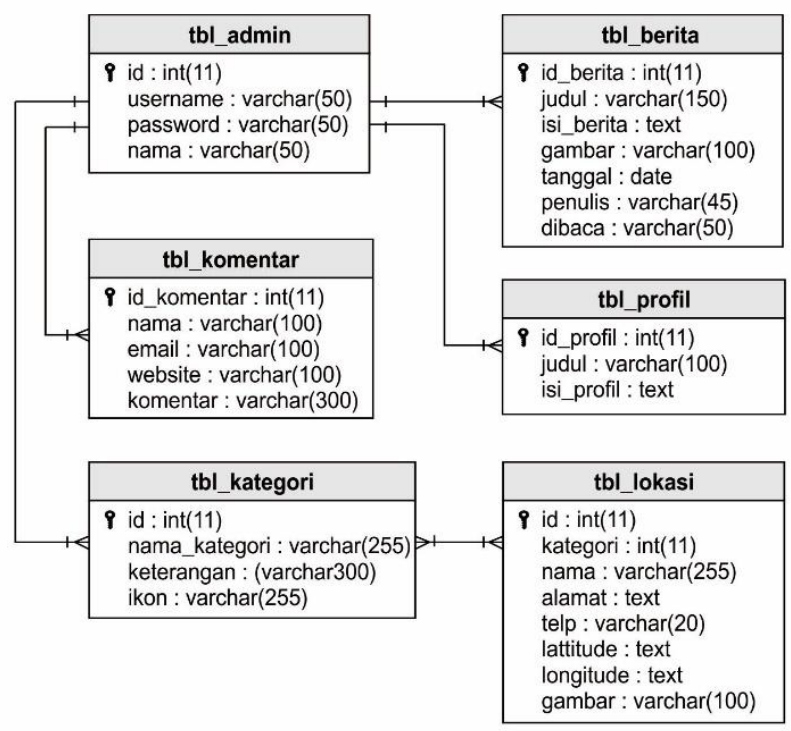

Gambar 6. ER Diagram

\section{Pembuatan WebGIS}

Berdasarkan data penelitian yang sudah didapatkan pada langkah sebelumnya, maka dibuat database webGIS menggunakan phpMyAdmin dengan XAMPP sebagai localhost. PhpMyAdmin adalah sebuah $M y S Q L$ client yang merupakan aplikasi web dan pada umumnya terdapat pada server PHP seperti XAMPP maupun server komersial yang lain [13]. Database webGIS pada penelitian ini terdiri dari 6 tabel yaitu admin, berita, kategori, komentar, lokasi, profil dan rute.

Stuktur kode WebGIS wisata Jakarta Barat disusun menggunakan kerangka atau framework codeIgniter. CodeIgniter adalah sebuah aplikasi berbasis open source yang berupa framework dengan struktur MVC (Model, View, Controller) yang digunakan untuk membangun sebuah website yang dinamis menggunakan PHP. Dengan menggunakan framework ini dapat memudahkan pengembang web untuk menghasilkan sebuah website dinamis secara cepat dan mudah dibandingkan dengan membangun kode dari awal [14].

WebGIS wisata Jakarta Barat terdapat dua tampilan utama, yaitu halaman admin dan halaman user. Untuk bisa mengakses halaman admin maka diharuskan memasukan user dan password pada halaman login webGIS (gambar 7). Apabila sudah berhasil menginput user dan pasword maka akan muncul halaman dashboard admin webGIS. Pada halaman dashboard bisa dilakukan proses editing data profil webGIS, penambahan dan pengeditan lokasi wisata Jakarta Barat, penambahan dan pengeditan kategori wisata, penambahan rute lokasi wisata, dan penambahan atau pengeditan berita serta pengelolaan komentar pada webGIS. Profil webGIS yang dimaksud adalah keterangan

https://doi.org/10.30743/infotekjar.v4i1.1486 dari webGIS wisata Jakarta Barat ini yang meliputi latar belakang dan tujuan dari pembuatan webGIS.

Lokasi wisata yang dimaksud adalah wisata yang ada di Jakarta Barat yang terdiri dari 5 kategori, yaitu wisata sejarah dan budaya, wisata religi, wisata keluarga, wisata kuliner dan wisata belanja. Sedangkan berita yang dimaksud adalah perincian dari semua titik wisata yang dimuat dalam webGIS ini lengkap dengan kontak dan link menuju rute perjalanan di Google Maps.

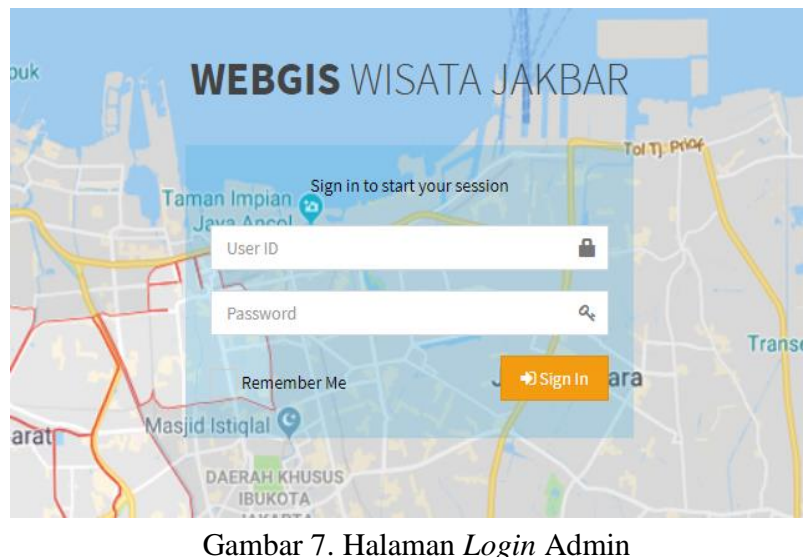

Pada halaman tambah lokasi wisata pada dashboard admin webGIS (gambar 8) terdapat isian untuk penambahan data wisata berupa nama wisata, kategori, alamat lengkap, nomor telepon, lattitude dan longitude lokasi. Yang menjadi inti dari webGIS ini adalah lokasi titik lokasi wisata yang diinput berdasarkan lattitude dan longitude yang didapatkan dari aplikasi Google Maps. Latitude secara terjemahan adalah garis lintang dan longitude adalah garis bujur. Garis lintang disebut juga garis khatulistiwa sedangkan garis bujur adalah garis yang digunakan untuk menentukan waktu atau tanggal di dunia [15].

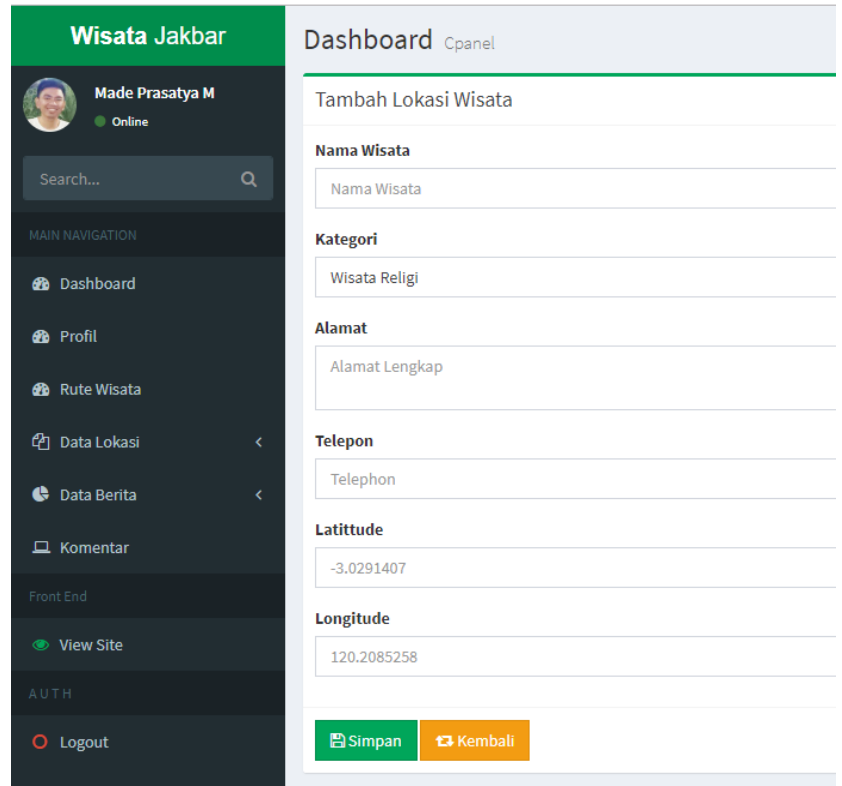

Gambar 8. Halaman Tambah Lokasi Pada Dashboard Admin

Pada tampilan halaman user, webGIS wisata Jakarta Barat terbagi menjadi tujuh halaman utama yaitu halaman beranda, profil, lokasi wisata, berita dan halaman komentar. Tampak pada gambar 9 adalah tampilan beranda webGIS. Pada bagian utama 
halaman beranda terdapat daftar lokasi wisata dan peta persebaran wisata Jakarta Barat.

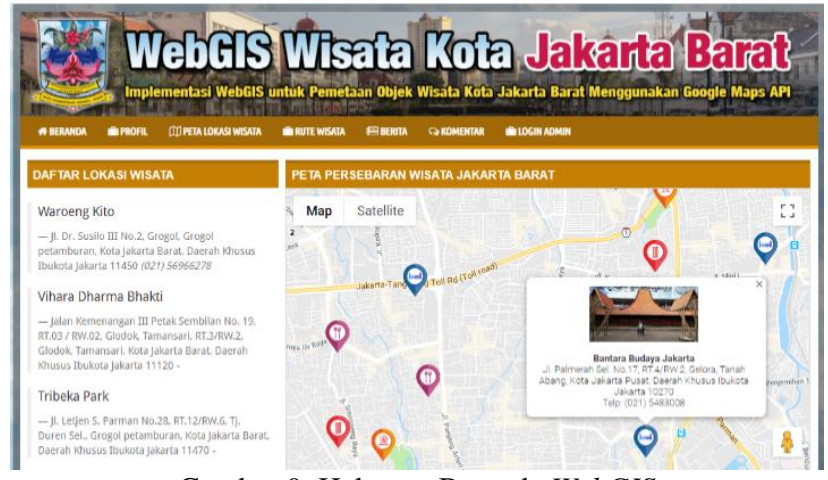

Gambar 9. Halaman Beranda WebGIS

Daftar lokasi wisata terdapat 52 titik wisata yang terbagi menjadi 5 kategori wisata. Peta persebaran wisata merupakan tampilan dari peta Google Maps hasil input koordinat lattitude dan longitude pada dashboard admin webGIS. Tiap kategori wisata diwakili dengan gambar ikon yang berbeda-beda yang ketika dipilih salah satu titiknya akan muncul jendela pop up yang berisi detail dari wisata tersebut. Halaman beranda juga dilengkapi dengan footer yang berisi widget berita terbaru, berita populer dan kontak.

Pada halaman profil akan ditampilkan profil webGIS wisata Jakarta Barat meliputi penjelasan singkat tentang kota Jakarta Barat dan tujuan pembuatan webGIS. Halaman peta lokasi wisata menampilkan nama wisata, alamat wisata serta titik lokasi wisata pada peta Google Maps. Pada halaman berita terdapat informasi mengenai wisata di Jakarta Barat baik berupa sejarah singkat maupun informasi yang lainnya dan dilengkapi dengan gambar atau foto pendukung. Pada kolom berita juga terdapat pengelompokan berupa widget berita terbaru maupun berita populer. Berita populer diurutkan berdasarkan jumlah pengaksesnya. Pada halaman komentar, pengunjung atau pengakses webGIS bisa dengan mudah memberikan komentar dan akan langsung ditayangkan pada webGIS. Rute tiap lokasi wisata Jakarta Barat melalui aplikasi Google Maps ditampilkan pada halaman rute wisata dengan cara mengakses button Google Maps (gambar 10).

\section{RUTE LOKASI WISATA DI GOOGLE MAPS}

Berikut adalah daftar wisata kota Jakarta Barat yang terdapat pada webCIS ini, silahkan klik pada button untuk menuju halaman rute pada aplikasi google maps.
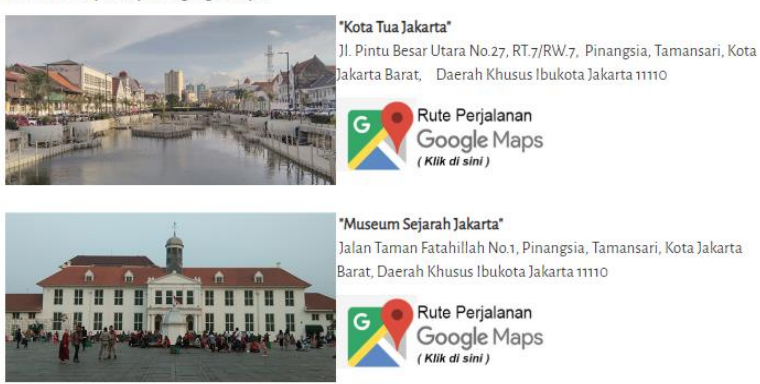

Gambar 10. Halaman Rute Wisata pada WebGIS

Pembuatan webGIS wisata Jakarta Barat ini menggunakan server lokal atau disebut localhost menggunakan XAMPP sehingga webGIS bisa diakses melalui browser lokal. Ketika webGIS sudah berhasil diakses melalui server lokal maka langkah selanjutnya adalah melakukan upload data ke webhosting agar webGIS bisa diakses melalui media internet. Proses upload data menggunakan FTP FileZilla yang merupakan aplikasi bebas atau open source sehingga mudah didapatkan maupun digunakan. Hasil akhir WebGIS wisata kota Jakarta Barat dapat diakses melalui browser internet dengan mengunjungi laman www.wisatajakbar.web.id.

\section{Uji Aplikasi}

\section{Uji Fungsionalitas Sistem}

Pengujian fungsionalitas sistem dilakukan dengan cara mengakses aplikasi dengan menggunakan beberapa browser internet yang berbeda. Dalam penelitian ini menggunakan browser Google Chrome, Mozilla Firefox, Opera dan Microsoft Edge pada perangkat komputer dan menggunakan browser Google Chrome, Firefox Rocket, Opera Mini dan Dolphin pada perangkat smartphone. Hasil dari uji sistem dapat dilihat pada tabel 1:

Tabel 1. Hasil Uji Sistem

\begin{tabular}{lll}
\hline \multicolumn{1}{c}{ Browser } & Perangkat & Hasil \\
\hline $\begin{array}{l}\text { Google Chrome } \\
\text { 74.0.3729.131 }\end{array}$ & Komputer & Berhasil \\
\hline $\begin{array}{l}\text { Mozilla Firefox } 65.0 .2 \\
\text { Opera 58.0.3135.132 }\end{array}$ & Komputer & Berhasil \\
\hline $\begin{array}{l}\text { Microsoft Edge } \\
\text { 42.17134.1.0 }\end{array}$ & Komputer & Berhasil \\
\hline $\begin{array}{l}\text { Google Chrome } \\
\text { 70.0.3538.80 Smartphone }\end{array}$ & Berhasil \\
\hline Firefox Rocket 1.0.1710 & Smartphone & Berhasil \\
\hline Opera Mini 36.2 & Smartphone & Berhasil \\
\hline Dolphin 11.5.6 & Smartphone & Berhasil \\
\hline
\end{tabular}

\section{Uji Usabilitas}

Pada uji usabilitas, dilakukan pembagian kuesioner untuk mengetahui tingkat kebergunaan webGIS. Kuesioner berisi pertanyaan-pertanyaan seputar penggunaan webGIS yang dibuat dengan bahasa yang sederhana supaya tidak menyulitkan responden dalam mengisinya. Adapun pengukuran kuesioner menggunakan metode Likert's [16]. Kuesioner disebarkan secara online menggunakan bantuan Google Forms kepada 40 responden yang dipilih secara acak melalui media sosial online. Terdapat 10 pertanyaan yang dibagi menjadi 3 kategori yaitu efektifitas aplikasi, kemudahan pengguna dan kepuasan pengguna.

Bobot kuesioner yang digunakan adalah skala 1-5 :

$\begin{array}{lll}\text { SS } & =\text { Sangat Setuju } & \text { bobot }=5 \\ \text { S } & =\text { Setuju } & \text { bobot }=4 \\ \text { CS } & =\text { Cukup Setuju } & \text { bobot }=3 \\ \text { TS } & =\text { Tidak Setuju } & \text { bobot }=2 \\ \text { STS } & =\text { Sangat Tidak Setuju } & \text { bobot }=1\end{array}$

Sedangkan penghitungan rekapitulasi kuesioner menggunakan rumus :

\section{Jumlah responden $x$ Bobot}

Jumlah pertanyaan $x$ total jumlah responden

Pada tabel 2, 3 dan 4 berikut ditampilkan hasil rekapitulasi ketiga kuesioner tersebut dari sejumlah 40 responden : 
Tabel 2. Rekapitulasi Kuesioner Efektifitas

\begin{tabular}{|c|c|c|c|c|c|c|c|}
\hline \multirow[t]{2}{*}{ No } & \multirow{2}{*}{$\begin{array}{l}\text { Komponen } \\
\text { Penilaian }\end{array}$} & \multicolumn{5}{|c|}{ Rating } & \multirow[t]{2}{*}{ Total } \\
\hline & & 1 & 2 & 3 & 4 & 5 & \\
\hline 1 & $\begin{array}{l}\text { Apakah } \\
\text { tampilan } \\
\text { webGIS ini } \\
\text { menarik }\end{array}$ & 10 & 18 & 9 & 3 & 0 & 0,97 \\
\hline 2 & $\begin{array}{l}\text { Apakah } \\
\text { lokasi wisata } \\
\text { sudah sesuai? }\end{array}$ & 9 & 6 & 18 & 5 & 2 & 0,84 \\
\hline 3 & $\begin{array}{l}\text { Apakah } \\
\text { webGIS } \\
\text { membantu } \\
\text { mendapatkan } \\
\text { informasi } \\
\text { wisata }\end{array}$ & 13 & 19 & 6 & 2 & 0 & 1,02 \\
\hline 4 & $\begin{array}{l}\text { Apakah peta } \\
\text { Google Maps } \\
\text { pada webGIS } \\
\text { ini } \\
\text { membantu? }\end{array}$ & 16 & 15 & 4 & 2 & 0 & 0,98 \\
\hline & & & & & & & 3,81 \\
\hline
\end{tabular}

Tabel 3. Rekapitulasi Kuesioner Kemudahan

\begin{tabular}{|c|c|c|c|c|c|c|c|}
\hline \multirow[t]{2}{*}{ No } & \multirow{2}{*}{$\begin{array}{l}\text { Komponen } \\
\text { Penilaian }\end{array}$} & \multicolumn{5}{|c|}{ Rating } & \multirow[t]{2}{*}{ Total } \\
\hline & & 1 & 2 & 3 & 4 & 5 & \\
\hline 1 & $\begin{array}{l}\text { Apakah } \\
\text { webGIS ini } \\
\text { mudah } \\
\text { diakses? }\end{array}$ & 10 & 15 & 12 & 3 & 0 & 0,95 \\
\hline 2 & $\begin{array}{l}\text { Apakah data } \\
\text { lokasi wisata } \\
\text { mudah } \\
\text { ditemukan? }\end{array}$ & 7 & 14 & 14 & 3 & 2 & 0,88 \\
\hline 3 & $\begin{array}{l}\text { Apakah } \\
\text { halaman } \\
\text { komentar } \\
\text { mudah } \\
\text { digunakan? }\end{array}$ & 12 & 16 & 8 & 4 & 0 & 0,98 \\
\hline 4 & $\begin{array}{l}\text { Apakah data } \\
\text { berita wisata } \\
\text { mudah } \\
\text { diakses? }\end{array}$ & 13 & 12 & 11 & 3 & 1 & 0,96 \\
\hline \multicolumn{7}{|c|}{ Total Nilai } & 3,77 \\
\hline
\end{tabular}

Tabel 4. Rekapitulasi Kuesioner Kepuasan

\begin{tabular}{|c|c|c|c|c|c|c|c|}
\hline \multirow[t]{2}{*}{ No } & \multirow{2}{*}{$\begin{array}{l}\text { Komponen } \\
\text { Penilaian }\end{array}$} & \multicolumn{5}{|c|}{ Rating } & \multirow[t]{2}{*}{ Total } \\
\hline & & 1 & 2 & 3 & 4 & 5 & \\
\hline 1 & $\begin{array}{l}\text { Apakah Anda } \\
\text { puas dengan } \\
\text { adanya webGIS } \\
\text { ini? }\end{array}$ & 10 & 15 & 12 & 2 & 1 & 1,89 \\
\hline 2 & $\begin{array}{l}\text { Apakah Anda } \\
\text { puas dengan } \\
\text { manfaat } \\
\text { webGIS ini? }\end{array}$ & 12 & 13 & 7 & 5 & 3 & 1,83 \\
\hline & Tot & Nil & & & & & 3,72 \\
\hline
\end{tabular}

Pada penilaian kuesioner efektifitas aplikasi terdapat empat poin pertanyaan yang ditujukan kepada 40 responden. Kriteria penilaian dibagi menjadi 5 rating dengan penilaian bintang 5 adalah kriteria tidak efektif sampai dengan penilaian bintang 1 dengan kriteria sangat efektif. Dari tabel 2 dapat disebutkan bahwa peringkat tertinggi terdapat pada fungsi webGIS sebagai media informasi wisata di Jakarta Barat dengan jumlah poin 1,02 dan peringkat terendah pada kesesuaian lokasi wisata dengan jumlah poin 0,84 . Hasil akhir kuesioner efektifitas aplikasi mendapatkan total nilai 3,81 yang berarti masuk dalam kriteria "cukup efektif".

Pada penilaian kuesioner kemudahan pengguna terdapat empat poin pertanyaan yang ditujukan kepada 40 responden. Kriteria penilaian dibagi menjadi 5 rating dengan penilaian bintang 5 adalah kriteria tidak mudah sampai dengan penilaian bintang 1 dengan kriteria sangat mudah. Dari tabel 3 dapat disebutkan bahwa peringkat tertinggi terdapat pada kemudahan mengakses halaman komentar dengan jumlah poin 0,98 dan peringkat terendah pada kemudahan pencarian lokasi wisata dengan jumlah poin 0,88. Hasil akhir kuesioner kemudahan pengguna mendapatkan total nilai 3,77 yang berarti masuk dalam kriteria "cukup mudah".

Pada penilaian kuesioner kepuasan pengguna terdapat dua poin pertanyaan yang ditujukan kepada 40 responden. Kriteria penilaian dibagi menjadi 5 rating dengan penilaian bintang 5 adalah kriteria tidak puas sampai dengan penilaian bintang 1 dengan kriteria sangat puas. Dari tabel 4 dapat disebutkan hasil akhir kuesioner kepuasan pengguna mendapatkan total nilai 3,72 yang berarti masuk dalam kriteria "cukup puas".

\section{KESIMPULAN}

Penelitian ini menghasilkan sebuah webGIS wisata Jakarta Barat yang bisa diakses melalui browser internet dengan mengunjungi laman www.wisatajakbar.web.id. Wisata yang termuat dalam webGIS berupa wisata budaya dan sejarah, wisata kuliner, wisata belanja, wisata keluarga dan wisata religi. Aplikasi ini dibangun menggunakan Framework CodeIgniter sebagai kerangka utama. Sedangkan pengelolaan koordinat lokasi wisata menggunakan metode Location Based Service (LBS) dengan memanfaatkan CodeIgniter Google Maps v3 library dimana dalam struktur library tersebut terdapat Google Maps API key yang digunakan untuk menampilkan peta Google Maps pada website.

Pengujian dari aplikasi webGIS dilakukan dengan cara uji sistem dan uji usabilitas. Pada uji sistem dapat disimpulkan bahwa webGIS dapat diakses melalui beberapa browser internet yang berbeda baik pada komputer maupun smartphone. Sedangkan pada uji usabilitas dari sejumlah 40 responden didapatkan hasil uji efektifitas aplikasi sejumlah 3,81 poin, uji kemudahan pengguna 3,77 poin dan uji kepuasan pengguna sejumlah 3,72 poin. Dengan mengacu pada penilaian dengan skala 1 sampai 5 maka dapat disimpulkan bahwa aplikasi webGIS wisata Jakarta Barat ini termasuk kategori "cukup efektif", "cukup mudah" dan "cukup puas".

Implementasi webGIS dalam pemetaan wisata kota Jakarta Barat bisa memudahkan masyarakat dalam mencari informasi wisata di Jakarta Barat dikarenakan webGIS dapat diakses dengan mudah 
melalui browser internet tanpa menggunakan software GIS Teknologi webGIS yang merupakan perpaduan antara desain web dan pemetaan juga dapat memudahkan pengguna dalam memahami informasi yang ada di webGIS wisata Jakarta Barat.

Adapun saran yang dapat disampaikan adalah agar aplikasi ini dapat dikembangkan lagi dengan cara bekerja sama dengan Dinas Pariwisata setempat, sehingga diharapkan akan semakin banyak titik lokasi wisata di kota Jakarta Barat yang bisa ditampilkan dalam aplikasi webGIS ini. Pengembangan aplikasi ini juga bisa membuat informasi yang ada di webGIS ini menjadi up to date.

\section{DAFTAR PUSTAKA}

[1] Pemerintah Kota Administrasi Jakarta Barat, "Sejarah," [Online]. Available: https://barat.jakarta.go.id/v12/?p=sejarah. [Accessed 5 April 2019].

[2] B. Hasan, S. Andri and Hani'ah, "Aplikasi WebGIS Pariwisata menggunakan Google Map API di Kabupaten Lombok Timur," Jurnal Geodesi Undip, vol. 4, no. 4, pp. 815,2015

[3] D. B. Firmansya, F. Ramdani and H. Tolle, "WebGIS Application of Geospatial Technology for Tourist Destination in Malang," Journal of Telecommunication, Electronic and Computer Engineering, vol. 10, no. 2-3, pp. 47-51, 2018.

[4] M. Sholeh and T. Maulana, "Desain dan Implementasi Sistem Informasi Wisata Goa berbasis Google Map," Jurnal Teknologi dan Sains Terapan SIMETRIS, vol. 9, no. 1, pp. 20-27, 2015.

[5] Riyanto, Pengembangan Aplikasi Sistem Informasi Geografis Berbasis Desktop dan Web, Yogyakarta: Gava Media, 2009.

[6] Z. R. Maharoesman, D. Suwardhi and A. Indrajaya, "Pembangunan Sisem Informasi Geografis Berbasis Web untuk Kegiatan Ekskavasi Situs Warisan Budaya Indonesia," Jurnal Konservasi Cagar Budaya Borobudur, vol. 7, no. 2, pp. 35-43, 2013.

[7] G. R. Syarif, B. Dirgantoro and R. Latuconsina, "Perancangan dan Implementasi Sistem Informasi Geografis Berbasis Web di Kecamatan Dayeuhkolot Sub Layanan Kesehatan," e-Proceeding of Engineering, vol. 5, no. 2, pp. 2420-2427, 2018.

[8] S. Irawan and A. Zowtler, "Aplikasi Wisata Batam Menggunakan Layanan Location Based Service Berbasis Webgis," Jurnal Teknomatika, vol. 10, no. 1, pp. 81-94, 2017.

[9] Y. Rachmawa, T. Kurniawan and S. Pradhityo, "Aplikasi Pengembangan Sistem Informasi Bangunan Cagar Budaya Di Kota Yogyakarta Berbasis Web Mobile Dan Location Based Service," Jurnal Penelian BAPPEDA Kota Yogyakarta, pp. 54-63, 2016.

[10] K. and A. , Asyik Berinternet dengan Beragam Layanan Google, Yogyakarta : Penerbit Andi, 2008.

[11] E. Triandini and I. G. Suardika, Step by Step Desain Proyek Menggunakan UML, Yogyakarta: CV. Andi Offset, 2012.
[12] C. Prianto and M. Kusnadi, "Penerapan Algoritma Dijkstra Untuk Menentukan Rute Terbaik Pada Mobile E-Parking Berbasis Sistem Informasi Geografis," Jurnal Informatika: Jurnal Pengembangan IT (JPIT), vol. 3, no. 3, pp. 329-335, 2018.

[13] A. Zaki and S. Community, 36 Menit Belajar Komputer PHP dan MySQL, Jakarta : Elex Media Komputindo, 2008.

[14] S. and V. Putratama, Pemrograman Web dengan menggunakan PHP dan Framework CodeIgniter, Yogyakarta: Deepblish, 2018.

[15] R. M. Awangga, Pengantar Sistem Informasi Geografis, Bandung: Kreatif Industri Nusantara, 2019.

[16] R. Pamungkas and S. , "Evaluasi Kualitas Website Program Studi Sistem Informasi Universitas PGRI Madiun Menggunakan Webqual 4.0," Jurnal INTENSIF, vol. 3, no. 1, pp. 22-31, 2019. 